\title{
Targeted delivery of doxorubicin-utilizing chitosan nanoparticles surface-functionalized with anti-Her2 trastuzumab
}

This article was published in the following Dove Press journal:

International Journal of Nanomedicine

I3 September 201 I

Number of times this article has been viewed

\section{Parisa Yousefpour' \\ Fatemeh Atyabi ${ }^{2}$ \\ Ebrahim Vasheghani- \\ Farahani $^{3}$ \\ Ali-Akbar Mousavi \\ Movahedi' \\ Rassoul Dinarvand ${ }^{2}$}

'Department of Biotechnology, Faculty of Science, University of Tehran,

${ }^{2}$ Nanotechnology Research Centre, Faculty of Pharmacy, Tehran University of Medical Sciences, ${ }^{3}$ Biotechnology Group, Department of Chemical Engineering Faculty of Engineering, Tarbiat Modares University, Tehran, Iran
Correspondence: Fatemeh Atyabi Faculty of Pharmacy, Tehran University of Medical Sciences, Tehran 14174, Iran Tel +982I 66959052

Fax +9821 66959052

Email atyabifa@tums.ac.ir
Background: Targeting drugs to their sites of action to overcome the systemic side effects associated with most antineoplastic agents is still a major challenge in pharmaceutical research. In this study, the monoclonal antibody, trastuzumab, was used as a targeting agent in nanoparticles carrying the antitumor drug, doxorubicin, specifically to its site of action.

Methods: Chitosan-doxorubicin conjugation was carried out using succinic anhydride as a crosslinker. Trastuzumab was conjugated to self-assembled chitosan-doxorubin conjugate (CS-DOX) nanoparticles (particle size, $200 \mathrm{~nm}$ ) via thiolation of lysine residues and subsequent linking of the resulted thiols to chitosan. Conjugation was confirmed by gel permeation chromatography, differential scanning calorimetry, Fourier transform infrared spectroscopy, and ${ }^{1} \mathrm{H}$ nuclear magnetic resonance spectroscopy studies. Dynamic light scattering, transmission electron microscopy, and zeta potential determination were used to characterize the nanoparticles.

Results: CS-DOX conjugated nanoparticles had a spherical shape and smooth surface with a narrow size distribution and core-shell structure. Increasing the ratio of doxorubicin to chitosan in the conjugation reaction gave rise to a higher doxorubicin content but lower conjugation efficiency. Trastuzumab-decorated nanoparticles (CS-DOX-mAb) contained $47 \mu \mathrm{g} / \mathrm{mg}$ doxorubicin and $33.5 \mu \mathrm{g} / \mathrm{mg}$ trastuzumab. Binding of trastuzumab to the nanoparticles was further probed thermodynamically by isothermal titration calorimetry. Fluorescence microscopy demonstrated enhanced and selective uptake of CS-DOX-mAb by Her2 ${ }^{+}$cancer cells compared with nontargeted CS-DOX nanoparticles and free drug.

Conclusion: Antibody-conjugated nanoparticles were shown to discriminate between Her $2^{+}$ and Her2 ${ }^{-}$cells, and thus have the potential to be used in active targeted drug delivery, with reduction of drug side effects in Her2 $2^{+}$breast and ovarian cancers.

Keywords: chitosan, doxorubicin, self-assembled nanoparticles, active targeting, trastuzumab

\section{Introduction}

The main objective in anticancer drug development is to deliver therapeutic agents in a targeted and selective fashion to their site of action, and to decrease adverse effects and enhance efficacy. Over recent years, nanoparticulate carrier systems have aroused ever increasing interest in this area. ${ }^{1,2}$ These targeted nanosystems can deliver drugs in a passive or active way. Passive targeted drug delivery takes advantage of the poor lymphatic systems of tumor tissues and their leaky vasculature with pore sizes ranging from 100 to $780 \mathrm{~nm} .^{3-5}$ These characteristics enable what is called the "enhanced permeability and retention" effect, which allows enhanced deposition of delivery nanovehicles at the site of a solid tumor. Active targeted drug delivery on the other hand is achieved via covalent conjugation of targeting molecules on the nanoparticle 
surface which can recognize and bind to specific ligands expressed specifically in cancer cells. One such ligand is human epidermal growth factor receptor 2 (Her2) or ErbB2 (Neu), the expression of which is amplified in about $30 \%$ of breast cancers and $20 \%$ of ovarian cancers, and this receptor is expressed weakly in normal adult tissues. ${ }^{6-8}$

Trastuzumab (Herceptin ${ }^{\circledR}$ ) is a humanized monoclonal antibody directed against the Her2 receptor, and is the only Her2-targeted therapy approved by the US Food and Drug Administration for the treatment of advanced breast cancer. Combination of trastuzumab with conventional chemotherapy leads to increased response rates in comparison with trastuzumab alone..$^{9-11}$ In addition, according to some clinical trials, anthracycline-based chemotherapy demonstrated more successful results in Her ${ }^{+}$women. ${ }^{12}$ However, trastuzumab has been shown to aggravate anthracycline-induced cardiotoxicity, and thus cannot be given concomitantly with anthracyclines, including doxorubicin. ${ }^{13,14}$ Conjugation of trastuzumab to doxorubicin-carrying nanoparticles allows transport of the chemotherapeutic agent specifically to tumor cells and reduced their adverse cardiotoxic effects. Furthermore, in such nanoparticulate formulations, trastuzumab is intended to act as a targeting ligand rather than as a therapeutic agent and thus its concentration is far below its therapeutic dose. Previous studies have shown promising results for either cancer therapy or imaging via trastuzumab decoration of such nanoparticles as dextran iron oxide nanoparticles, ${ }^{15}$ poly(d,1-lactide-co-glycolide)/montmorillonite nanoparticles, ${ }^{16}$ poly(dl-lactic acid) nanoparticles, ${ }^{17}$ and human serum albumin nanoparticles. ${ }^{18-20}$

Chitosan is a carbohydrate polymer with the desirable properties of biodegradability and biocompatibility that have made it a candidate polymer for preparation of drug delivery carriers. ${ }^{21-29}$ Several methods have been developed for the preparation of doxorubicin delivery systems based on chitosan, ${ }^{30}$ which include dextran sulfate-chitosan hydrogel nanoparticles, glycol-chitosan nanoaggregates, oleoyl-chitosan nanoparticles, chitosan-poly(acrylic acid) hollow nanospheres, and stearic acid-grafted chitosan oligosaccharide micelles.

However, in targeted delivery systems, covalent conjugation of drug to its carrier is more advantageous than drug encapsulation because it prevents premature drug release into the blood circulation before its delivery to the target site. In this study, chitosan-doxorubicin conjugate (CS-DOX) nanoaggregates were prepared via covalent conjugation of doxorubicin to chitosan. Trastuzumab was conjugated to the nanoaggregates, and the efficacy of the resulting actively targeted nanocarriers was studied in vitro.

\section{Methods and materials Materials}

Doxorubicin (purity approximately 98.5\%) was purchased from RPG Life Sciences Ltd (Ankleshwar, India). Chitosan, with a medium molecular weight and deacetylation of about 96\%, was supplied by Fluka, Germany. Sodium nitrite, hydrochloric acid, glacial acetic acid, sodium hydroxide, succinic anhydride, 1-ethyl-3-(3-dimethyl amino-propyl) carbodiimide hydrochloride (EDC), N-hydroxysuccinimide (NHS), acetonitrile, triethylamine, and ethyl acetate and chloroform (analytical grade) were obtained from Merck, Darmstadt, Germany. Total protein kit (product code TP0200) and sulfosuccinimidyl 4-(N-maleimidomethyl) cyclohexane1-carboxylate were purchased from Sigma (St Louis, MO). Trastuzumab was purchased from Roche, Mannheim, Germany. Cell lines were provided by the Pasteur Institute, Tehran, Iran. All other chemicals were of analytical grade. Deionized water was used throughout.

\section{Conjugation of doxorubicin to chitosan}

CS-DOX conjugates were synthesized using succinic anhydride as a spacer. Succinic anhydride was employed to react with and convert the amine group of doxorubicin to carboxylic residues, ie, succinic acid residues. The resulted succinyl doxorubicin (SDOX) was then introduced to chitosan via amide bond formation mediated by EDC and NHS.

At first, $120 \mathrm{kDa}$ chitosan was prepared according to the depolymerization method described by Peniston and Johnson. ${ }^{31}$ Briefly, $10 \mathrm{~mL}$ nitrite sodium solution $(1 \mathrm{mg} / \mathrm{mL})$ was added to $100 \mathrm{~mL} 2 \%(\mathrm{w} / \mathrm{v})$ chitosan solution in $6 \%(\mathrm{v} / \mathrm{v})$ acetic acid. The depolymerization reaction was allowed to proceed for 1 hour while stirring and was then stopped by raising the $\mathrm{pH}$ to 9 using $5 \mathrm{~N} \mathrm{NaOH}$. The precipitated whiteyellowish chitosan was then filtered and washed thoroughly with acetone. The filtrate was redissolved in a minimum volume of acetic acid $0.1 \mathrm{~N}$ and was dialyzed against deionized water $(2 \times 2 \mathrm{~L}$ for 90 minutes and $1 \times 2 \mathrm{~L}$ overnight $)$. The dialyzed product was lyophilized at $50^{\circ} \mathrm{C}$ and $0.01 \mathrm{mbar}$ (LyoTrap plus, LTE Scientific, Chorley, UK).

To prepare SDOX, $40 \mathrm{mg}$ doxorubicin $\mathrm{HCl}$ was dissolved in dry acetonitrile to which $70 \mu \mathrm{L}$ triethylamine and $690 \mathrm{mg}$ succinic anhydride in $3 \mathrm{~mL}$ dry acetonitrile was added. The reaction was allowed to complete by 15 hours stirring at $4^{\circ} \mathrm{C}$ in the dark. Afterwards, the solution was distributed between $10 \mathrm{~mL}$ sodium bicarbonate $5 \%(\mathrm{w} / \mathrm{v})$ solution and $40 \mathrm{~mL}$ chloroform. The chloroform phase was decanted and the residual solution was extracted by ethyl acetate after lowering the $\mathrm{pH}$ using $1 \mathrm{M} \mathrm{HCl}$. Ethyl acetate was evaporated by a rotary evaporator to obtain SDOX. 
For covalent conjugation of SDOX to chitosan, $200 \mathrm{mg}$ chitosan was hydrated in $2 \mathrm{~mL}$ of $1 \mathrm{M} \mathrm{HCl}$. Deionized water was added to give a final chitosan concentration of $1 \%(\mathrm{w} / \mathrm{v})$. SDOX in $2 \%$ sodium bicarbonate was added to obtain an $\mathrm{SDOX} / \mathrm{CS}(\mathrm{w} / \mathrm{w})$ ratio of $20 \%, 10 \%, 5 \%, 2.5 \%$, and $1 \%$, followed by addition of EDC and NHS ( 5 molar equivalents with respect to SDOX). pH was adjusted to 6.6 using $5 \mathrm{~N}$ $\mathrm{NaOH}$ and the reaction was allowed to stir for 36 hours at room temperature. Afterwards, unreacted components were removed by extensive dialysis against deionized water. CS-DOX was concentrated via centrifugation with $30 \mathrm{kDa}$ cutoff centrifugal ultrafilters (Millipore Corporation, Billerica, MA) at $4000 \mathrm{~g}$ and $10^{\circ} \mathrm{C}$ for 15 minutes. The CS-DOX were stored at $4^{\circ} \mathrm{C}$ until further use (Figure 1).
Conjugates with an initial CS-DOX (w/w) ratio of $20 \%$, $10 \%, 5 \%, 2.5 \%$, and $1 \%$ were named as CS-DOX-1, CS-DOX-2, CS-DOX-3, CS-DOX-4, and CS-DOX-5, respectively.

\section{Gel permeation chromatography}

The molecular weight of the depolymerized chitosan was determined by gel permeation chromatography. A PL Aquagel-OH mixed gel filtration column $(300 \mathrm{~mm} \times 7.5 \mathrm{~mm}$ internal diameter, pore size $8 \mu \mathrm{m}$ ) from Agilent Technologies, Santa Clara, $\mathrm{CA}$, was used. All chromatograms were generated on an Agilent 1100 liquid chromatographer (Agilent Technologies), and the eluting fraction was monitored using a refractive index signal detector. The lyophilized powder of depolymerized chitosan was dissolved in $300 \mathrm{mM}$ acetate buffer, $\mathrm{pH} 4.5$, with a final

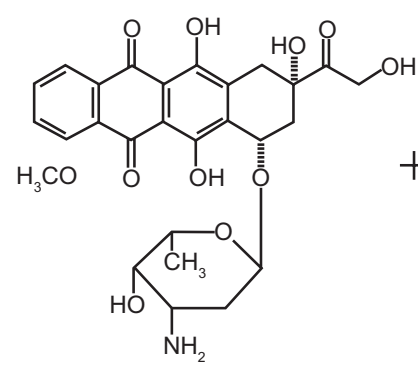

Doxorubicin
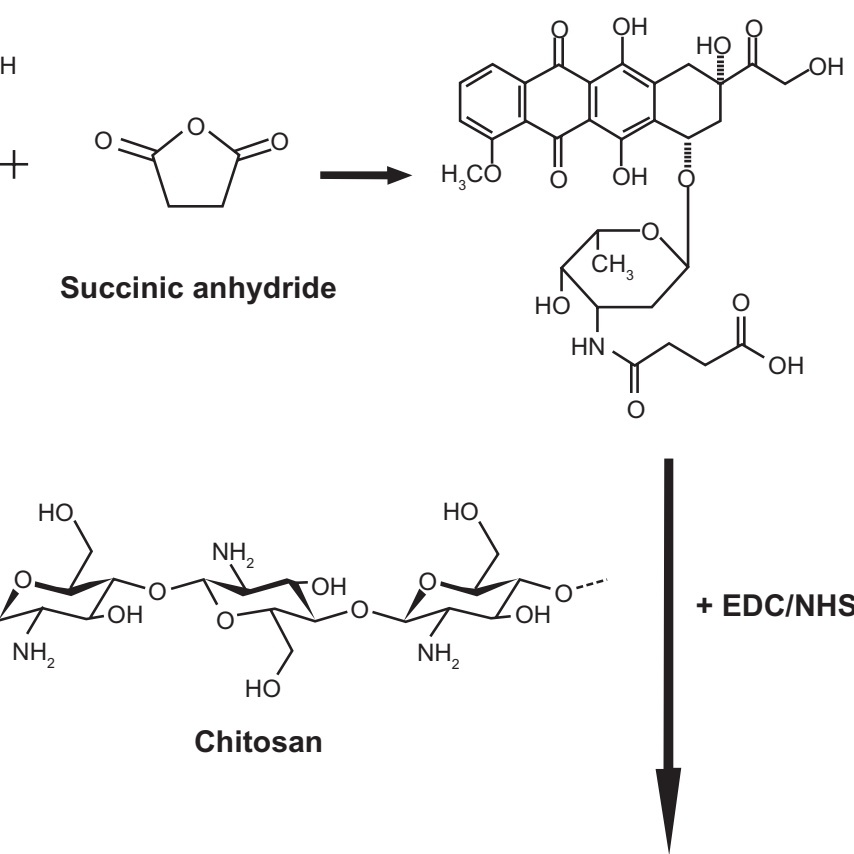

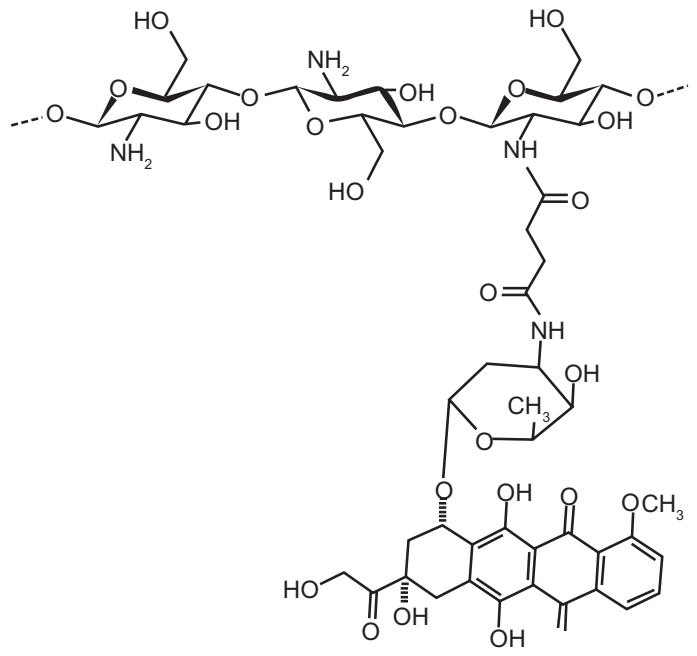

Figure I Schematic illustration of the procedures for the synthesis of chitosan-doxorubicin conjugate.

Abbreviations: EDC, I-ethyl-3-(3-dimethyl amino-propyl) carbodiimide hydrochloride; NHS, N-hydroxysuccinimide. 
concentration of $3 \mathrm{mg} / \mathrm{mL}$, and was chromatographed at a flow rate of $5 \mathrm{~mL} / \mathrm{min}$. Chromatograms were generated and analyzed by EZChrom Elite software (Version 3.1, Scientific Software, Pleasanton, CA) using the narrow method. Gel permeation chromatography analysis was also carried out to examine covalent conjugation of doxorubicin to chitosan.

\section{Fourier transform infrared spectroscopy}

To study the chemical reactions between doxorubicin and succinic anhydride, doxorubicin and rotary-dried SDOX were pressed into $\mathrm{KBr}$ discs and examined by Fourier transform infrared spectroscopy using a Nicolet spectrometer (Nicolet Magna IR 550, Madison, WI).

\section{'H nuclear magnetic resonance spectroscopy}

${ }^{1} \mathrm{H}$ nuclear magnetic resonance (NMR) spectra were recorded on a Bruker FT-80 spectrometer (Bruker, Rheinstetten, Germany) and chemical shifts $(\delta)$ are in parts per million (ppm) relative to internal tetramethylsilane. To this end, $\mathrm{CDCl} 3$ was used as the solvent for SDOX while doxorubicin, chitosan, and CS-DOX were dissolved in $\mathrm{D}_{2} \mathrm{O}$.

\section{Differential scanning calorimetry}

The thermal behavior of CS-DOX was studied by differential scanning calorimetry using a 822e differential scanning calorimeter (Mettler-Toledo, Greifensee, Switzerland). Samples were purged with dry nitrogen at a flow rate of $10 \mathrm{~mL} / \mathrm{min}$ and were heated in the temperature range $25^{\circ} \mathrm{C}-450^{\circ} \mathrm{C}$ at a heating rate of $10^{\circ} \mathrm{C} / \mathrm{min}$.

\section{Preparation of self-assembled nanoparticles}

CS-DOX conjugates were dissolved in deionized water at a concentration of $5 \mathrm{mg} / \mathrm{mL}$, and were gently stirred for one hour at room temperature. In addition, effect of concentration of conjugate was investigated by preparation of selfassembled nanoparticles using different concentrations of CS-DOX-2 $(0.25,1,5,10$, and $20 \mathrm{mg} / \mathrm{mL})$.

\section{Determination of conjugation efficiency and drug content}

Five hundred microliters of concentrated conjugates were placed on cover slips and dried in an oven (Memmert INB 400 , Schwabach, Germany) at $50^{\circ} \mathrm{C}$ for three hours. The cover slips were weighed afterwards, and knowing the initial weight of the cover slip, the mg of the conjugates was calculated. Quantification of doxorubicin was achieved via spectrophotometry at $480 \mathrm{~nm}$ (Scinco S-3100, Seoul, Korea). The conjugation efficiency and doxorubicin content of the CS-DOX conjugates was determined applying the following equations:

$$
\begin{aligned}
& \begin{array}{l}
\text { Conjugation } \\
\text { efficiency }(\%)
\end{array}=\frac{\text { weight of drug found conjugated }}{\text { weight of total drug used }} \times 100 \\
& \underset{(\% \mathrm{w} / \mathrm{w})}{\text { Drug content }}=\frac{\text { weight of drug found conjugated }}{\text { weight of conjugate }} \times 100
\end{aligned}
$$

\section{Measurement of particle size, polydispersity, and zeta potential}

The hydrodynamic mean diameter, polydispersity index, and zeta potential of the nanoparticles were measured by dynamic light scattering and laser Doppler electrophoresis using a Zetasizer (Nano-ZS, Malvern, Worcestershire, UK). All dynamic light scattering measurements were performed at a wavelength of $633 \mathrm{~nm}$ at $25^{\circ} \mathrm{C}$ with an angle detection of $90^{\circ}$. All measurements were done in triplicate.

\section{Scanning electron microscopy}

The surface morphology of the nanoparticles was imaged using a scanning electron microscope (XL 30, Philips, Eindhoven, the Netherlands). One drop of the nanoparticle preparation was layered on the scanning electron microscope stub and allowed to dry in air at room temperature. The dried nanoparticles were then coated with gold metal using a sputter coater (SCD 005, Bal-Tec, Balzers, Switzerland).

\section{Transmission electron microscopy}

A transmission electron microscope (CEM 902A, Zeiss, Oberkochen, Germany) was used to get a better idea of the inner structure of the self-assembled nanoparticles. The nanoparticle suspension was deposited on copper grids, subsequently negatively stained using $0.5 \%$ phosphotungstic acid, air dried, and viewed under the transmission electron microscope.

\section{Thiolation of trastuzumab and quantification of immobilized thiol groups} Trastuzumab thiolation was carried out using a 100-fold molar excess of 2-iminothiolane (Traut's reagent). The trastuzumab monoclonal antibody was prepared in $50 \mathrm{mM}$ phosphate buffer ( $\mathrm{pH} 8$ ) containing $\mathrm{NaCl} 0.15 \mathrm{M}$. To each $5 \mathrm{~mL}$ of trastuzumab solution $(2 \mathrm{mg} / \mathrm{mL}), 458 \mu \mathrm{L}$ Traut's reagent $(2 \mathrm{mg} / \mathrm{mL})$ was added. The thiolation reaction was stirred gently for 2 hours at room temperature. Unreacted Traut's reagent was excluded by centrifugation three times with $30 \mathrm{kDa}$ cutoff centrifugal 
ultrafilters (Millipore Corporation) at $4000 \mathrm{~g}$ and $10^{\circ} \mathrm{C}$ for 15 minutes.

The number of thiol groups added to the monoclonal antibody was subsequently dosed by Ellman's test as follows. The Ellman reagent, with a final concentration of $10 \mathrm{mM}$, was dissolved in $0.1 \mathrm{M}$ phosphate buffer ( $\mathrm{pH}$ 8). Ellman's reagent $100 \mu \mathrm{L}$ was added to $400 \mu \mathrm{L}$ of $2 \mathrm{mg} / \mathrm{mL}$ monoclonal antibody solution in phosphate buffer $(0.1 \mathrm{M}, \mathrm{pH} 8)$. After 15 minutes of incubation, the absorbance was measured at $450 \mathrm{~nm}$ using a spectrophotometer (Scinco S-3100). A standard calibration curve was obtained from 10-200 $\mu \mathrm{M} \mathrm{N}$-acetyl L-cysteine.

\section{Preparation of trastuzumab-modified nanoparticles}

CS-DOX-2 nanoparticles were dispersed in phosphate buffer $(0.1 \mathrm{M}, \mathrm{pH} 7.2)$ at a concentration of $5 \mathrm{mg} / \mathrm{mL}$ and were activated using $2 \mathrm{mg}$ of the heterobifunctional crosslinker, sulfosuccinimidyl 4-(N-maleimidomethyl) cyclohexane1-carboxylate. After 3 hours of incubation at room temperature, sulfhydryl-reactive nanoparticles were purified by centrifugation $\left(4000 \mathrm{~g}, 10^{\circ} \mathrm{C}, 15\right.$ minutes) using $100 \mathrm{kDa}$ cutoff centrifugal ultrafilters (Millipore Corporation). The coupling reaction was achieved by adding $500 \mu \mathrm{L}$ of thiolated trastuzumab $2 \mathrm{mg} / \mathrm{mL}$ to $4 \mathrm{~mL}$ nanoparticle suspension $5 \mathrm{mg} / \mathrm{mL}$, followed by three hours of incubation at room temperature. The trastuzumab-modified nanoparticles (CS-DOX-mAb) were purified by centrifugation $(26,000 \mathrm{rpm}$, $10^{\circ} \mathrm{C}, 30$ minutes) and nonconjugated antibody in supernatant was quantified with using the Total Protein Kit (Micro Lowry, Onishi and Barr modification, Sigma).

\section{Isothermal titration calorimetry study}

Isothermal titration calorimetry experiments were conducted using an isothermal titration calorimetry instrument (VPITC, MicroCal, Northampton, MA). The titration vessel was made from stainless steel. Trastuzumab solution (39 $\mathrm{nM}$ ) was injected using a Hamilton syringe into the calorimetric titration vessel which contained $1.8 \mathrm{~mL}$ protein A $8.86 \mathrm{nM}$. Thin (0.15 mm inner diameter) stainless steel hypodermic needles, permanently fixed to the syringe, reached directly into the calorimetric vessel. Injection of the trastuzumab solution into the perfusion vessel was repeated 30 times, with $10 \mu \mathrm{L}$ per injection. The calorimetric signal was measured by a digital voltmeter which was part of a computerized recording system. The heat of each injection was calculated by the MicroCal Origin 7.0 software supplied with the instrument. The microcalorimeter was frequently calibrated electrically during the course of the study.

\section{Cell lines and culture conditions}

The Her2- human breast cancer cell line (MCF7) and Her2 ${ }^{+}$ ovarian carcinoma cell line (SKOV-3) were obtained from National Cell Bank of Iran (Pasteur Institute). Cells were maintained in RPMI-1640 culture medium supplemented with fetal bovine serum $10 \%$, penicillin 100 units $/ \mathrm{mL}$, and streptomycin $100 \mathrm{ng} / \mathrm{mL}$ at $37^{\circ} \mathrm{C}$ in a $5 \% \mathrm{CO}_{2}$ humidified incubator (New Brunswick Scientific, Edison, NJ).

\section{In vitro cytotoxicity assay}

The cytotoxicity of CS-DOX-2, CS-DOX-mAb, and free doxorubicin against SKOV-3 cells was evaluated using the tetrazolium-based colorimetric (MTT) assay. The tested concentrations were 8,40 , and $200 \mathrm{nM}$ doxorubicin equivalents. Cytotoxicity was then measured after 48 hours of exposure using the MTT method.

\section{Specificity of trastuzumab-modified nanoparticles}

The specificity of the trastuzumab-modified nanoparticles was investigated by comparing cellular uptake of CS-DOX-mAb into Her2-overexpressing SKOV-3 cells and Her2- MCF-7 cells. Cells were seeded in eight-well chamber slides and treated with CS-DOX-2, CS-DOX-mAb, and free doxorubicin at a concentration of $200 \mathrm{nM}$ doxorubicin equivalents. After 24 hours of incubation at $37^{\circ} \mathrm{C}$ in a humidified $5 \% \mathrm{CO}_{2}$ atmosphere, the medium was removed, the cells were fixed with methanol/ acetone $(\mathrm{v} / \mathrm{v} 9: 1)$ at $4^{\circ} \mathrm{C}$ for 30 minutes, rinsed in phosphatebuffered saline, and observed under a fluorescence microscope with a green filter ( $\lambda$ ext $490 \mathrm{~nm}$ and $\lambda$ em $520 \mathrm{~nm}$ ) and 1000 msec exposure time (BX40, Olympus, Tokyo, Japan).

\section{Results \\ Drug content and conjugation efficiency}

Doxorubicin was conjugated to chitosan using a succinic anhydride crosslinker. The drug content and conjugation efficiency of the prepared conjugates are shown in Table 1.

\section{Fourier transform infrared and 'H NMR spectroscopic study}

Fourier transform infrared and ${ }^{1} \mathrm{H}$ NMR spectra of doxorubicin, SDOX, and CS-DOX conjugates are depicted in Figure 2A, 2B, and $2 \mathrm{C}$. Observed signals for ${ }^{1} \mathrm{H}-\mathrm{NMR}$ of doxorubicin were:

${ }^{1} \mathrm{H}$ NMR (DMSO- d6): 7.90- $7.92\left(\mathrm{M}, 2 \mathrm{H}, \mathrm{H}_{3}, \mathrm{H}_{4}\right), 7.64$ $\left(\mathrm{d}, \mathrm{J}=7.2,1 \mathrm{H}, \mathrm{H}_{2}\right), 5.30\left(\mathrm{~S}, 1 \mathrm{H}, \mathrm{H}_{11}\right), 4.93\left(\mathrm{bs}, 1 \mathrm{H}, \mathrm{H}_{1}\right), 4.58$ (S, 2H, CO- $\left.\mathrm{CH}_{2}-\mathrm{OH}\right), 4.17(\mathrm{~m}, 1 \mathrm{H}), 3.93\left(\mathrm{~S}, 3 \mathrm{H}, \mathrm{OCH}_{3}\right)$, $2.32(1 \mathrm{H}), 2.92(\mathrm{~m}, 2 \mathrm{H}), 2.14(\mathrm{~m}, 2 \mathrm{H}), 1.92(\mathrm{~m}, 1 \mathrm{H}), 1.69$ (m, 1H), $1.18\left(\mathrm{~d}, 3 \mathrm{H}, \mathrm{CH}_{3}\right)$. 
Table I Drug content and conjugation efficiency of different chitosan-doxorubicin conjugates

\begin{tabular}{llll}
\hline $\begin{array}{l}\text { Conjugation } \\
\text { efficiency }\end{array}$ & $\begin{array}{l}\text { Drug } \\
\text { content }\end{array}$ & $\begin{array}{l}\text { DOX used/ } \\
\text { CS (w/w) }\end{array}$ & Conjugate \\
\hline $33 \%$ & $6.7 \%$ & $20 \%$ & CS-DOX-I \\
$41 \%$ & $4.1 \%$ & $10 \%$ & CS-DOX-2 \\
$54.6 \%$ & $2.37 \%$ & $5 \%$ & CS-DOX-3 \\
$62 \%$ & $1.55 \%$ & $2.5 \%$ & CS-DOX-4 \\
$69 \%$ & $0.69 \%$ & $1 \%$ & CS-DOX-5 \\
\hline
\end{tabular}

Abbreviations: CS, chitosan; DOX, doxorubicin.

\section{Calorimetric study of CS-DOX conjugation}

Thermograms of doxorubicin, chitosan, and CS-DOX are presented in Figure 3. A sharp endothermic peak located at $100^{\circ} \mathrm{C}$ was seen in all differential scanning calorimetry diagrams. The differential scanning calorimetry thermogram of chitosan showed another endothermic peak at $180^{\circ} \mathrm{C}$ and an exothermic peak at $370^{\circ} \mathrm{C}$. Doxorubicin was characterized by a relatively sharp endothermic peak at $200^{\circ} \mathrm{C}$ followed by two other endothermic peaks at higher temperatures. The differential scanning calorimetry curve for the CS-DOX conjugates exhibited an endotherm at $160^{\circ} \mathrm{C}$ and an exotherm at $340^{\circ} \mathrm{C}$.

\section{Gel permeation chromatograms}

Gel permeation chromatograms of chitosan and CS-DOX-2 are shown in Figure 4. Analysis of the resulting chromatograms using a narrow method revealed the molecular weights of chitosan and CS-DOX-2 to be 115.644 and $119.937 \mathrm{kDa}$, respectively.

\section{Size, zeta potential, and polydispersity index of CS-DOX nanoparticles}

All the prepared CS-DOX conjugated but CS-DOX-1 selfassembled into particles, the size, zeta potential, and

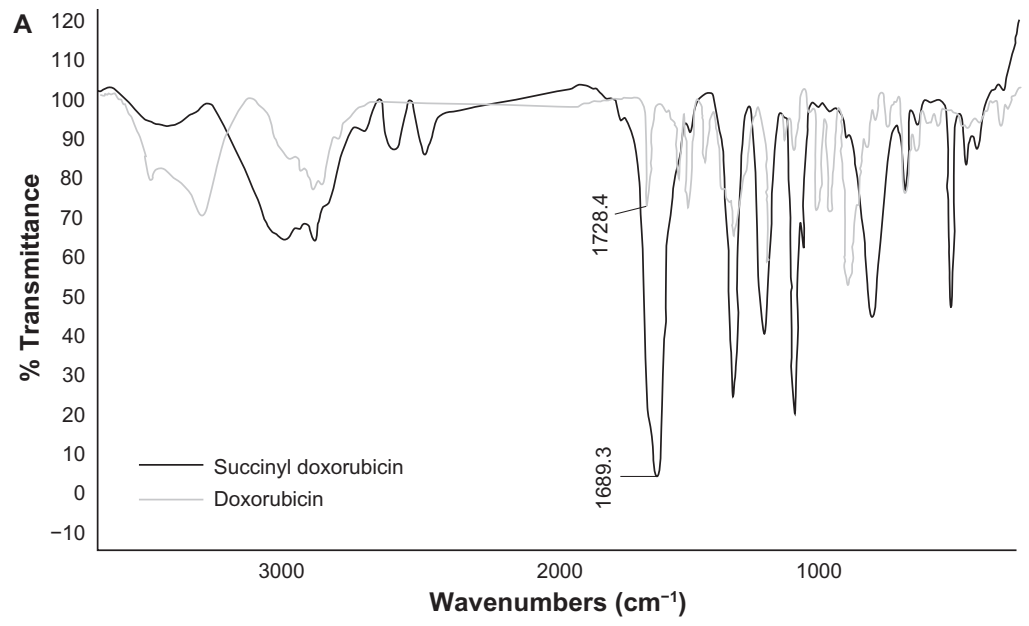

B ${ }^{1} \mathrm{H}$ NMR : Doxorubicin

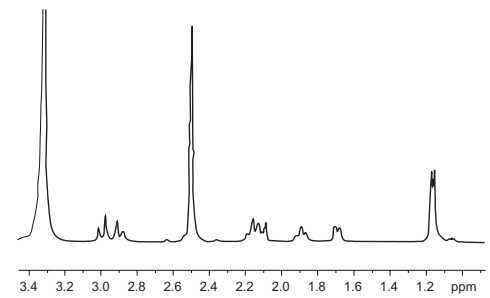

${ }^{1} \mathrm{H}$ NMR : Succinyl doxorubicin

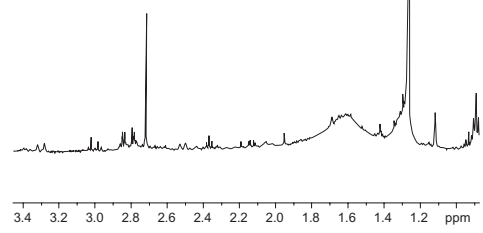

$\mathrm{C}^{1} \mathrm{H}$ NMR : Chitosan-doxorubicin conjugate

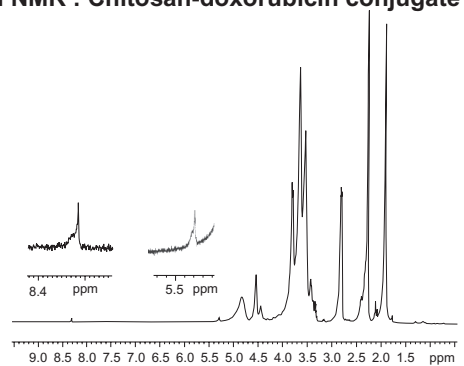

${ }^{1} \mathrm{H}$ NMR : Chitosan

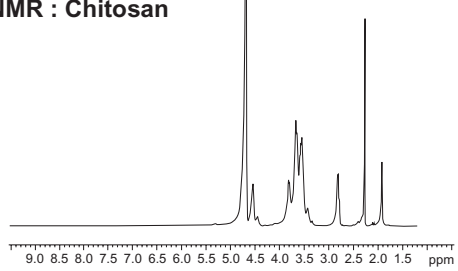

Figure 2 (A) Fourier transform infrared spectrum of doxorubicin and succinyl doxorubicin. (B) ' $\mathrm{H}$ nuclear magnetic resonance spectrum of doxorubicin and succinyl doxorubicin. (C) 'H nuclear magnetic resonance spectrum of chitosan and chitosan-doxorubicin conjugate. 


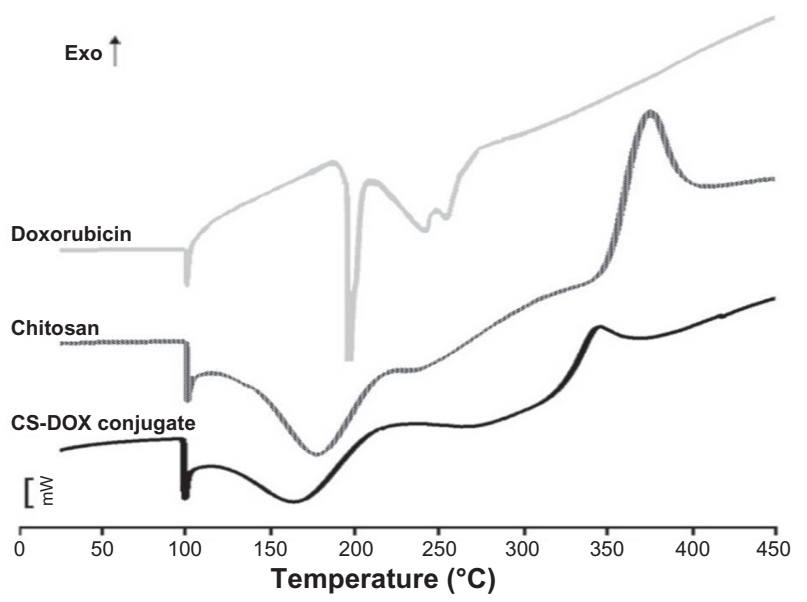

Figure 3 Differential scanning calorimetry thermograms of chitosan, doxorubicin and chitosan-doxorubicin conjugate (CS-DOX-2).

polydispersity indexes for which are given in Table 2. In addition, the effect of conjugate concentration on size of the prepared nanoparticles was investigated for CS-DOX-2, and the resulting data are shown in Figure 5.

\section{Surface and inner morphology of nanoparticles}

Scanning electron microscopic images as depicted in Figure $6 \mathrm{~A}$ revealed spherical and smooth-surfaced nanoparticles with a uniform size distribution. In addition, according to the transmission electron microscopic images, the inner morphology of CS-DOX self-assembled nanoparticles consists of a core-shell structure (Figure 6B).

\section{Trastuzumab coupling to CS-DOX nanoparticles}

Thiol groups required for the coupling reaction were added to trastuzumab by use of 2-iminothiolane. According to the

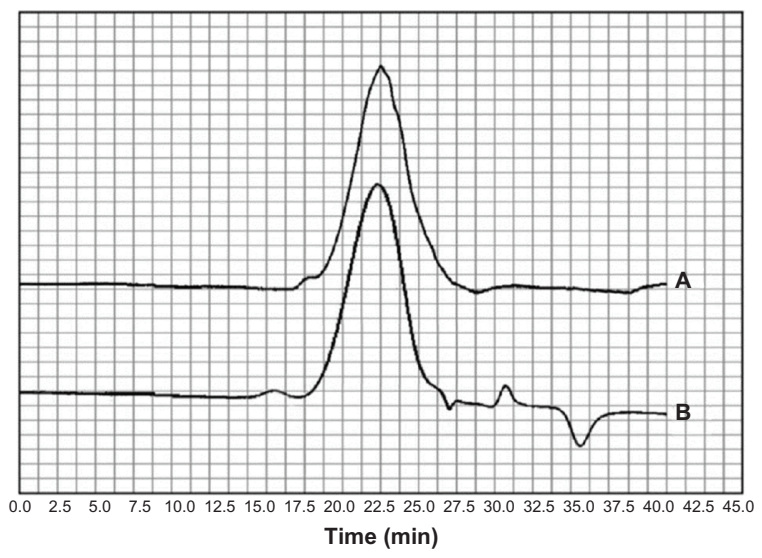

Figure $4 \mathrm{Gel}$ permeation chromatogram of (A) chitosan and (B) chitosandoxorubicin conjugates.
Table 2 Size, zeta potential, and polydispersity index of nanoaggregates prepared from different chitosan-doxorubicin conjugates

\begin{tabular}{lllll}
\hline PDI & $\begin{array}{l}\text { Zeta potential } \\
(\mathbf{m V})\end{array}$ & Size $(\mathbf{n m})$ & $\begin{array}{l}\text { Drug } \\
\text { content }\end{array}$ & Conjugate \\
\hline $0.108 \pm 0.054$ & $16.5 \pm 3$ & $228 \pm 21$ & $4.1 \%$ & CS-DOX-2 \\
$0.173 \pm 0.041$ & $17.5 \pm 4$ & $346 \pm 37$ & $2.37 \%$ & CS-DOX-3 \\
$0.083 \pm 0.047$ & $14.3 \pm 1$ & $493 \pm 26$ & $1.55 \%$ & CS-DOX-4 \\
$0.253 \pm 0.023$ & $18.1 \pm 4$ & $671 \pm 18$ & $0.69 \%$ & CS-DOX-5 \\
\hline
\end{tabular}

Abbreviations: CS-DOX, chitosan-doxorubicin conjugate; PDI, polydispersity index.

Ellman's test, 12.33 reactive thiol groups were linked to the lysine residues of the monoclonal antibody, which is equal to $13.7 \%$ of the lysine residues available. Furthermore, under the experimental conditions used, $67 \%$ of the monoclonal antibody molecules were attached to CS-DOX-2 nanoparticles. Each gram of the CS-DOX-mAb formulation obtained thus consisted of $47 \mu \mathrm{g}$ doxorubicin and $33.5 \mu \mathrm{g}$ trastuzumab.

\section{Interaction of nanoparticle-conjugated trastuzumab with protein $\mathrm{A}$}

Conjugation of the monoclonal antibody to the nanoparticles was analyzed by isothermal titration calorimetry taking advantage of the ability of the Fc fragment of an immunoglobulin molecule to interact with protein A. Isothermal titration calorimetry thermograms of protein A with free antibody and nanoparticle-conjugated monoclonal antibody are shown in Figure 7.

According to data analyzed by MicroCal Origin 7.0 software, the free monoclonal antibody-protein A interaction fitted well into a one-binding site model, while the conjugated monoclonal antibody-protein A interaction resulted in a minimum Chi-square value when the two-binding site model was applied. Thermodynamic parameters derived from corresponding models have been summarized in Table 3 . The

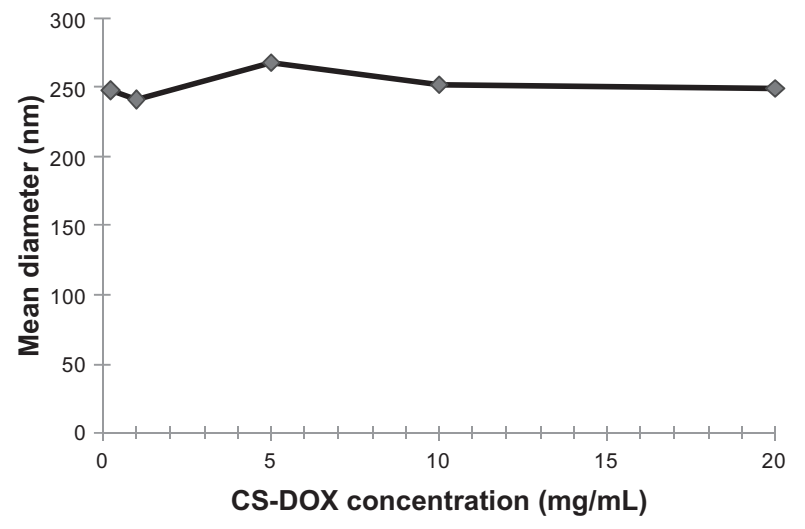

Figure 5 Effect of chitosan-doxorubicin conjugate concentration on hydrodynamic diameter of nanoaggregates.

Abbreviation: CS-DOX, chitosan-doxorubicin conjugate. 


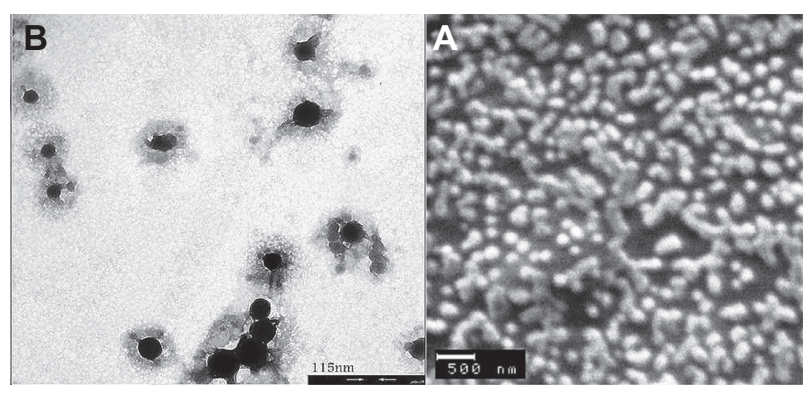

Figure 6 (A) Scanning electron micrographs of chitosan-doxorubicin conjugate (CS-DOX-2) nanoparticles and (B) transmission electron micrographs of CSDOX-2 nanoparticles.

affinity constant $(\mathrm{Ka})$, enthalpy changes $(\Delta \mathrm{H})$, and binding stoichiometry (n) of the interaction were used to determine the change in Gibb's free energy $(\Delta G)$ and change in entropy $(\Delta \mathrm{S})$ for each interaction event.

\section{Cytotoxicity assay}

The results of the cell viability MTT assay as presented graphically in histograms demonstrated increased cytotoxic activity of CS-DOX-mAb compared with CS-DOX-2.

A Time (min)

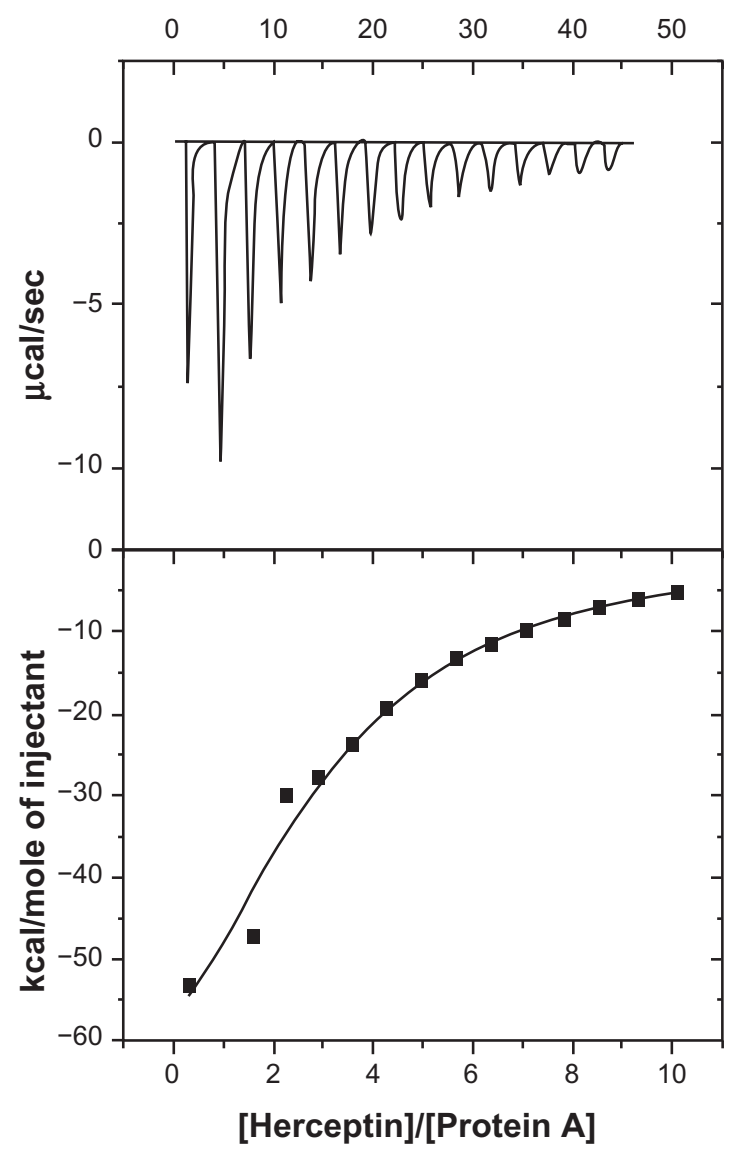

However, the growth inhibitory activity of doxorubicin in the CS-DOX-mAb formulation was reduced with respect to the equivalent concentration of free drug. Such differences were slightly more apparent for higher doses of drug (Figure 8).

\section{Cellular uptake}

Selective uptake of trastuzumab-modified nanoparticles by $\mathrm{Her}^{+}$cells was investigated by fluorescence microscopy utilizing the red fluorescence of doxorubicin. CS-DOX-mAb showed significantly higher entry into the Her2-overexpressing cell line, SKOV3, compared with the control MCF-7 cell line. Nontargeted nanoparticles, on the other hand, showed no obvious difference in this regard (Figure 9).

\section{Discussion}

This study aimed to develop a targeted delivery system for delivery of the chemotherapeutic drug, doxorubicin, to Her2-overexpressing cancer cells. CS-DOX conjugates were synthesized via carboxylation of doxorubicin and subsequent amidation of SDOX with amine groups on chitosan.

B Time ( $\min )$

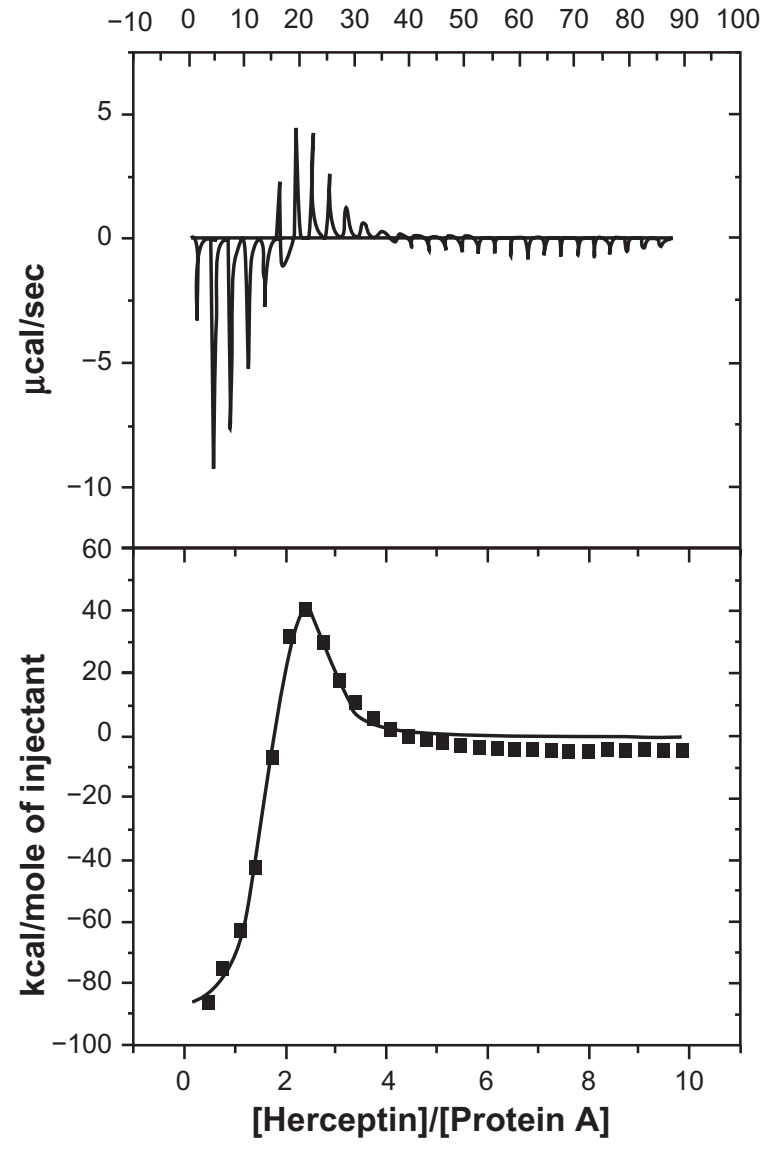

Figure $\mathbf{7}$ Isothermal titration calorimetry thermograms for interactions of protein A with (A) free antibody and (B) antibody attached to nanoparticles. 
Table 3 Interaction thermodynamic parameters of protein A with free and attached antibody

\begin{tabular}{lllll}
\hline $\begin{array}{l}\text { Nanoparticle-conjugated } \\
\text { monoclonal antibody }\end{array}$ & & $\begin{array}{l}\text { Free } \\
\text { monoclonal } \\
\text { antibody }\end{array}$ & Parameter \\
\cline { 1 - 2 } $\begin{array}{l}\text { Second } \\
\text { binding site }\end{array}$ & $\begin{array}{l}\text { First } \\
\text { binding site }\end{array}$ & & \\
\hline $1.07 \pm 0.26 \mathrm{I}$ & $\mathrm{I} .65 \pm 0.099$ & $2.78 \pm 0.469$ & ${ }^{\mathrm{a} n}$ \\
203.6 & 348.1 & & $5.7 \mathrm{I}$ & ${ }^{\mathrm{b}} \mathrm{K}\left(\times 10^{-4} \mathrm{M}^{-1}\right)$ \\
+68.1 & -93.9 & -104.8 & ${ }^{\mathrm{c}} \Delta \mathrm{H}^{\circ}(\mathrm{kcal} / \mathrm{mol})$ \\
-8.664 & -10.162 & -6.96 & ${ }^{\mathrm{d}} \Delta \mathrm{G}^{\circ}(\mathrm{kcal} / \mathrm{mol})$ \\
+0.318 & $-0.28 \mathrm{I}$ & -0.330 & ${ }^{\mathrm{e}} \Delta \mathrm{S}^{\circ}\left(\mathrm{kcal} / \mathrm{mol} /{ }^{\circ} \mathrm{K}\right)$ \\
\hline
\end{tabular}

Notes: abinding stoichiometry; 'bffinity constant; 'molar enthalpy change for the binding; ${ }^{d}$ molar free energy change; ${ }^{e}$ molar entropy change.

The appearance of peaks at $2.9 \mathrm{ppm}$ and $3.3 \mathrm{ppm}$ in the ${ }^{1} \mathrm{H}$ NMR spectrum for SDOX indicates the presence of a $-\mathrm{CH}_{2}-\mathrm{CH}_{2}$ group in addition to peaks belonging to the protons of doxorubicin (Figure 2B). Furthermore, appearance of new bands at around $1689 \mathrm{~cm}^{-1}$ which related to a carbonyl group $(\mathrm{C}=\mathrm{O})$ compared with that of the carbonyl group in doxorubicin $\left(1728 \mathrm{~cm}^{-1}\right)$ is attributed to the carbonyl group in succinate (Figure 2A).

Amide binding of SDOX to chitosan was carried out using EDC/NHS reagents. Conjugation was confirmed by gel permeation chromatography, differential scanning calorimetry, Fourier transform infrared spectroscopy, and ${ }^{1} \mathrm{H}$ NMR studies. Gel permeation chromatography as presented in
Figure 4 shows the increase in molecular weight of chitosan upon conjugation of doxorubicin moieties, and thus verifies the chemical nature of CS-DOX binding. In addition to peaks related to aliphatic protons in chitosan, the ${ }^{1} \mathrm{H}$ NMR spectrum of CS-DOX conjugate showed the appearance of aromatic protons of doxorubicin at $5.4 \mathrm{ppm}$ and $8.3 \mathrm{ppm}$ plus its methyl group at $1.17 \mathrm{ppm}$. Differential scanning calorimetry analysis of chitosan, doxorubicin, and CS-DOX conjugates was also carried out (Figure 3). A sharp peak at $100^{\circ} \mathrm{C}$ present in all three thermograms is attributed to the evaporation of humidity absorbed by the specimen. The differential scanning calorimetry thermogram of chitosan showed an endothermic peak at $180^{\circ} \mathrm{C}$ and an exothermic peak at $370^{\circ} \mathrm{C}$ which are ascribed, respectively, to hydrogenbonding dissociation and degradation of this polymer. ${ }^{32,33}$ The differential scanning calorimetry plot obtained for doxorubicin revealed an endothermic melting peak at $200^{\circ} \mathrm{C}$ with endothermic peaks of degradation appearing at higher temperatures. Conjugation of doxorubicin to chitosan led to a shift in hydrogen-bonding dissociation and degradation peaks of chitosan, while no trace of the doxorubicin peaks was observed in the differential scanning calorimetry thermogram of CS-DOX. The differential scanning calorimetry experiments thus corroborate conjugation of CS and DOX. In fact, addition of hydrophobic and voluminous doxorubicin molecules to the glucosamine units of chitosan weakens

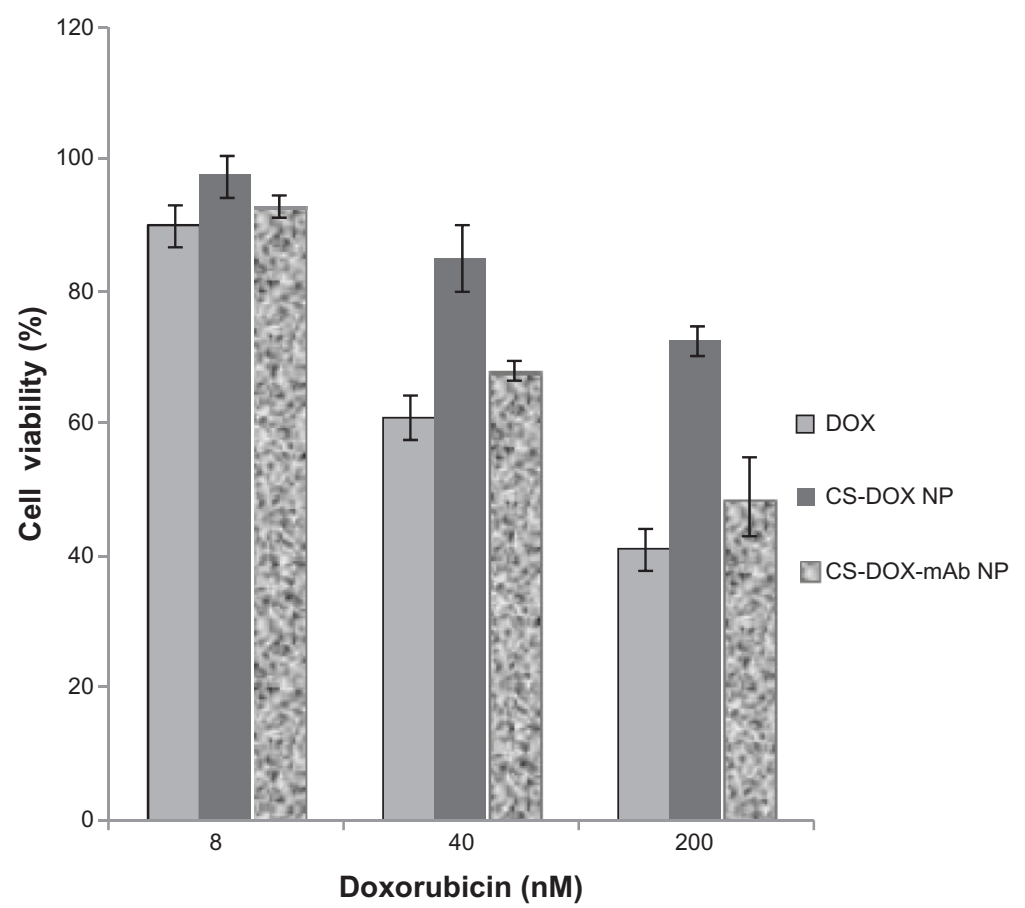

Figure 8 Effect of doxorubicin, chitosan-doxorubicin conjugated nanoparticles, and trastuzumab-decorated chitosan-doxorubicin conjugated nanoparticles at different concentrations on viability of SKOV-3 cell line.

Abbreviations: CS, chitosan; DOX, doxorubicin; NP, nanoparticles. 


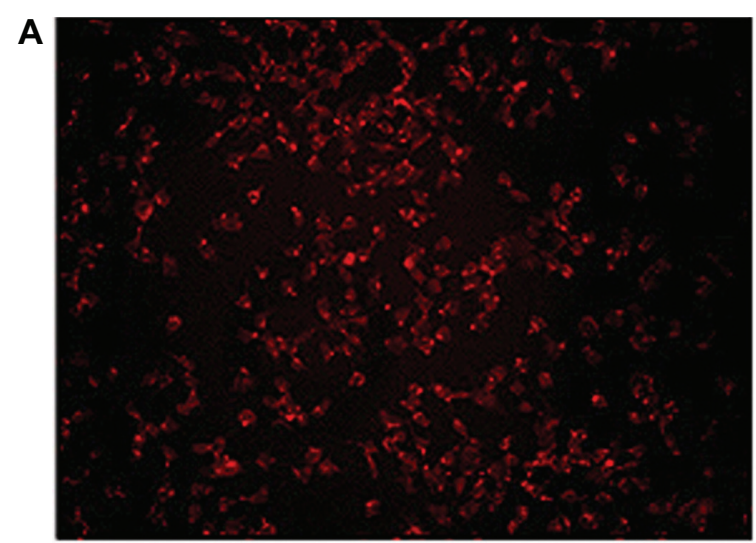

C

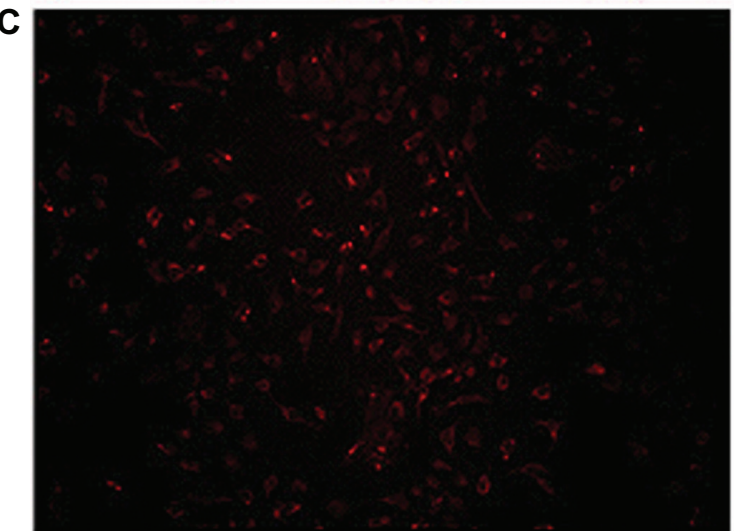

E

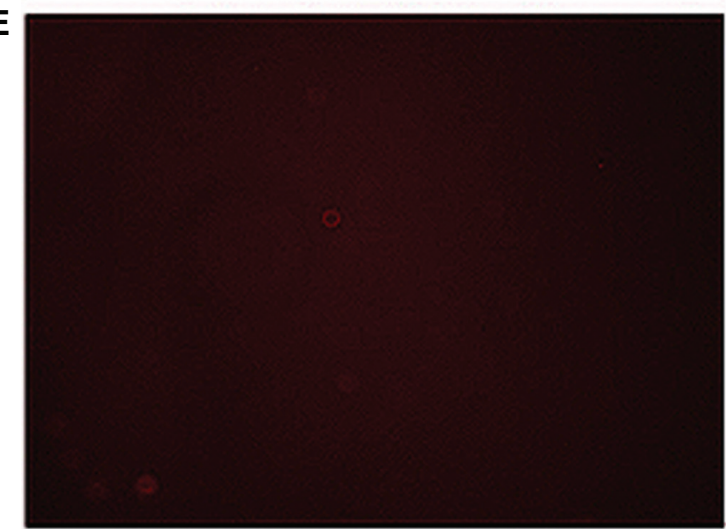

B

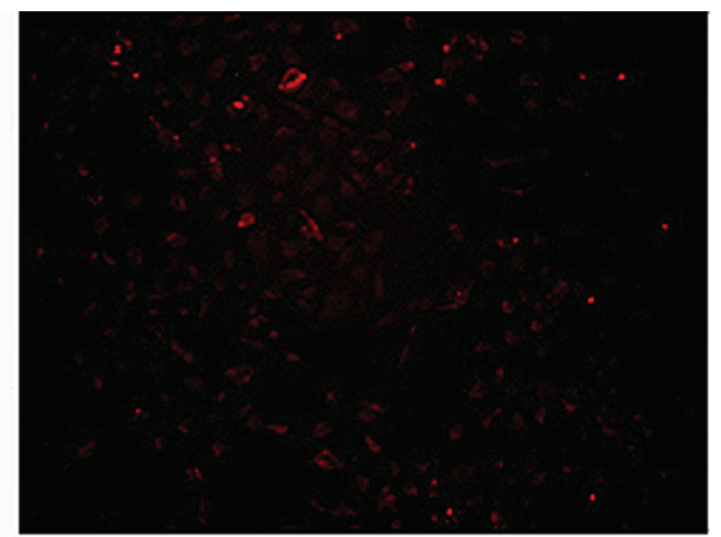

D

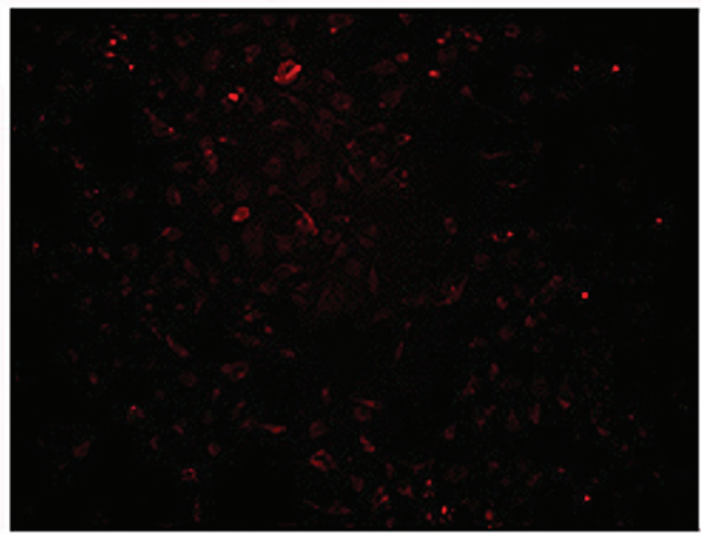

$\mathbf{F}$

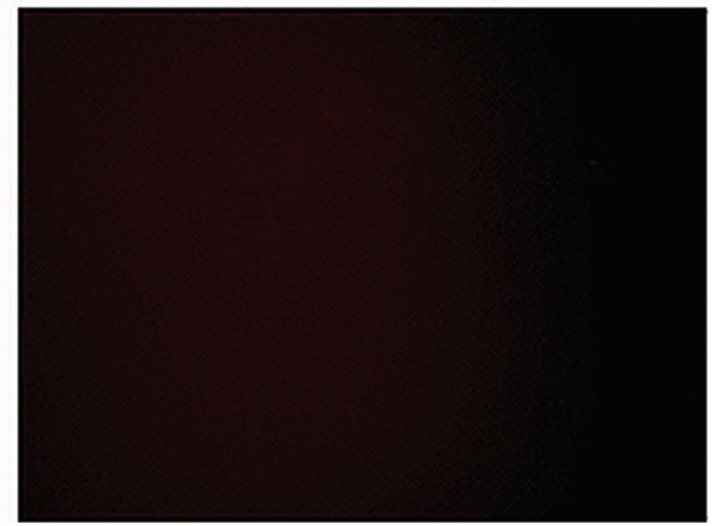

Figure 9 Fluorescence microscopy of cellular uptake of (A) trastuzumab-decorated chitosan-doxorubicin conjugated nanoparticles by SKOV-3 cell line, (B) trastuzumabdecorated chitosan-doxorubicin conjugated nanoparticles by MCF-7 cell line, (C) chitosan-doxorubicin conjugated nanoparticles by SKOV-3 cell line, and (D) chitosandoxorubicin conjugated nanoparticles by MCF-7 cell line. (E) SKOV-3 cells and (F) MCF-7 cells in cell culture medium served as negative controls.

the hydrogen binding between these units and renders the dissociation temperature lower. The absence of differential scanning calorimetry peaks for doxorubicin in the thermogram of CS-DOX confirms that no free drug exists in the CS-DOX conjugate.

Increasing the ratio of doxorubicin to chitosan in the conjugation reaction gave rise to a higher doxorubicin content but lower conjugation efficiency. All in all, CS-DOX conjugates with drug contents of $0.7 \%, 1.6 \%, 2.7 \%, 4.1 \%$, and $6.7 \%$ were synthesized. The amphiphilic property of CS-DOX conjugates in which the hydrophobic doxorubicin molecule is attached to the hydrophilic chitosan chain enables their self-assembly into nanoparticles. Such nanoaggregation behavior has been previously reported by Son et al and Hyung Park et al for glycol chitosan-doxorubicin conjugates. ${ }^{34,35}$ The exception is CS-DOX-1, the high doxorubicin content of which confers too high a degree of hydrophobicity, which leads to its precipitation in aqueous medium. Figure 10 is a schematic illustration of the selfassembly of CS-DOX conjugates, which is in accordance with the core-shell structures observed in transmission electron micrographs (Figure 6B). 


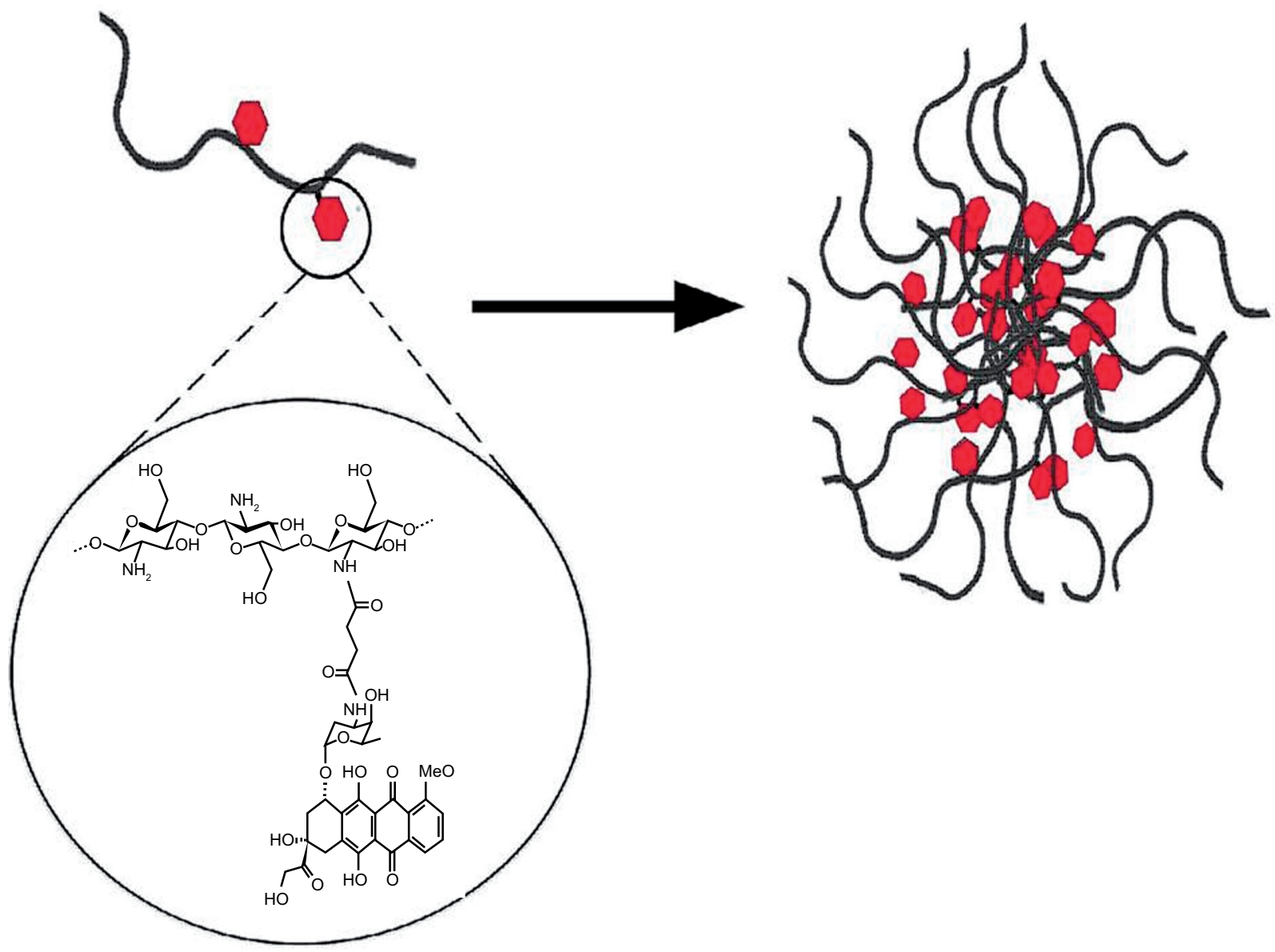

Figure I0 Schematic illustration of self-assembly of chitosan-doxorubicin conjugates into nanoparticles.

Scanning electron microscopic imaging also revealed smooth-surfaced and spherical nanoparticles with a narrow size distribution. The polydispersity index was determined to be satisfactorily low in nanoaggregates of all CS-DOX conjugates. The zeta potential showed no significant difference between the different types of conjugates, while the hydrodynamic diameter of the nanoparticles was measured to be larger in conjugates with higher drug content. In fact, hydrophobic interactions between the drug-bearing parts of the conjugates and hydrogen bonding between the bare carbohydrate skeleton and surrounding water molecules are the main contributing forces involved in self-assembly of CS-DOX conjugates. With higher drug contents, more portions of the conjugate chain take part in inner hydrophobic interactions and cause more compact aggregation of conjugates and consequently a smaller nanoaggregate size. In addition, the concentration of chitosan-drug conjugate showed no significant effect on size of the nanoaggregates. This indicates the micelle-like nature of these aggregates as the thermodynamics governing the packing of micellar structures have been shown to make the size of spherical micelles independent of concentration.
Size of the drug carriers plays a key role in their pharmacokinetics; the larger the nanoparticles, the higher the probability of their scavenging and clearance by macrophages. Nanoparticles larger than $300 \mathrm{~nm}$ activate the complement system and are cleared from the blood. Taking this into consideration, small-sized CS-DOX-2 nanoaggregates were used for the conjugation of trastuzumab, the targeting ligand.

Trastuzumab was conjugated to self-assembled CS-DOX-2 nanoparticles via thiolation of lysine residues by 2 -iminothiolane and subsequent linking of the resulting thiols to amine groups on chitosan. The targeted nanoparticles obtained contained $47 \mu \mathrm{g} / \mathrm{mg}$ doxorubicin and $33.5 \mu \mathrm{g} / \mathrm{mg}$ trastuzumab. Trastuzumab decoration led to no significant change in size or zeta potential of the nanoparticles, and the attached trastuzumab is embedded among the dynamic conjugate chains and so does not affect nanoparticle size.

Binding of trastuzumab to the nanoparticles was further probed thermodynamically by an isothermal titration calorimetry study of the interaction of protein $A$ with free and attached trastuzumab. Protein A is a $40-60 \mathrm{kDa}$ surface protein originally found in the cell wall of Staphylococcus aureus, 


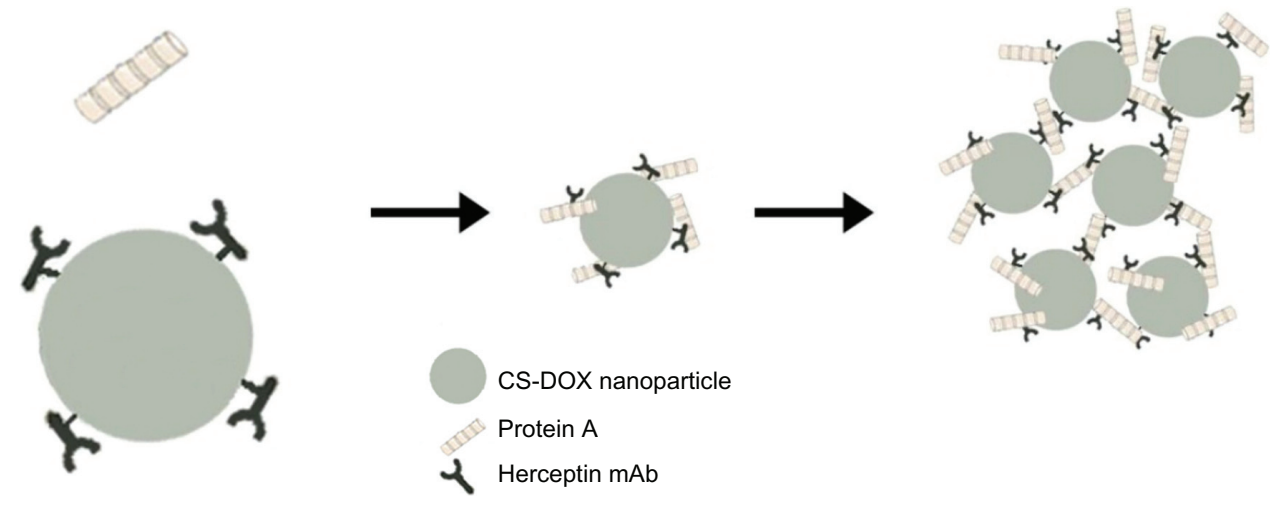

Figure I I Interaction of protein A with antibodies attached to the nanoparticle surface. Abbreviation: CS-DOX, chitosan-doxorubicin conjugate.

and binds with the Fc region of antibodies. This polypeptide chain consists of five homologous IgG-binding domains (from the N-terminus; E, D, A, B, and C). ${ }^{36}$ However, steric hindrance restricts concomitant access of all five binding sites to the antibodies. ${ }^{37}$ The isothermal titration calorimetry study gave a binding ratio of $3 \mathrm{~mol}$ antibody/mol protein A. The trastuzumab attached generated an isothermal titration calorimetry profile different from that of the free antibody, which confirms covalent conjugation of trastuzumab to nanoparticles. The isothermal titration calorimetry profile for the free trastuzumab-protein A interaction was composed of negative exothermic peaks. However, the interaction between the attached trastuzumab and protein A revealed initial exothermic peaks followed by exothermic peaks. A similar isothermal titration calorimetry thermogram was observed by Coles et al for the interaction of dendrimers with DNA. ${ }^{38}$ According to this group, the endothermic part of the thermogram is related to the precipitation of the dendrimer-DNA complex. Here, interaction of protein A with the trastuzumab attached led to an opaque appearance in the solution which clearly demonstrated the occurrence of aggregation and precipitation in the system. Attachment of several trastuzumab monoclonal antibodies to each nanoparticle along with the capacity of each protein A to bind to more than one monoclonal antibody brings the nanoparticles in close proximity to each other and leads to their aggregation into a macrostructure which precipitates (Figure 11).

Furthermore, the initial endothermic peaks demonstrate that the FC fragment of the attached trastuzumab monoclonal antibody has enough freedom to interact with protein A. This property may be taken advantage of for purification of such targeted delivery systems, using protein A affinity chromatography or for determination of monoclonal antibody on the surface of nanoparticles by techniques like surface plasmon resonance. ${ }^{39}$
In vitro cytotoxicity evaluation showed reduced efficacy of the CS-DOX nanoparticles with respect to free drug. This may be attributed to covalent and irreversible conjugation of doxorubicin to chitosan via a succinic anhydride crosslinker, as stated elsewhere. ${ }^{40,41}$ Free doxorubicin can penetrate the nuclear envelope, localize in nucleus and exert its cytotoxicity through its primary mechanism of action, ie, inhibition of topoisomerase II. However, when conjugated to chitosan, doxorubicin cannot access its target and consequently its cytotoxic efficiency is hampered.

On the other hand, fluorescence microscopy displayed enhanced and selective uptake of CS-DOX-mAb by Her2 ${ }^{+}$ cancer cells comparing with CS-DOX nontargeted nanoparticles. The enhanced cellular uptake partially compensated for the diminished effect of attached doxorubicin and improved the cytotoxicity of this doxorubicin nanodelivery system.

\section{Conclusion}

A novel, chitosan-based targeted drug delivery system has been developed. The anti-HER2 humanized antibody, trastuzumab, was used as the targeting moiety. The resulting amphiphilic polymer-drug conjugates with a doxorubicin content of $0.69 \%-4.1 \%(\mathrm{w} / \mathrm{w})$ were demonstrated to selfassemble into nanoparticles ranging from 200-700 nm in size depending on the doxorubicin content of the conjugate. Although covalent conjugation of doxorubicin to chitosan weakens its anticancer activity, antibody-conjugated nanoparticles were shown to discriminate between $\mathrm{Her}^{+}$and Her2 ${ }^{-}$cells and thus have potential applications in active targeted drug delivery and reduction of drug side effects in Her $2^{+}$breast and ovarian cancers. However, substitution of succinic anhydride with a $\mathrm{pH}$-sensitive crosslinker like cisaconityl anhydride ${ }^{40-42}$ or hydrazone bonds ${ }^{43,44}$ may be taken into consideration in future studies to achieve an actively targeted vector releasing its cargo drug at its site of action. 


\section{Acknowledgment}

The authors would like to thank the Nanotechnology Research Centre of Tehran University of Medical Sciences for supporting this research.

\section{Disclosure}

The authors report no conflicts of interest in this work.

\section{References}

1. Torchilin VP. Targeted pharmaceutical nanocarriers for cancer therapy and imaging. AAPS J. 2007;9(2):E128-E147.

2. Yokoyama M, Okano T. Introduction: targetable drug carriers: present status and a future perspective. Adv Drug Deliver Rev. 1996;21(2): 77-80.

3. Wahl RL, Cody RL, Hutchins GD, Mudgett EE. Primary and metastatic breast carcinoma: initial clinical evaluation with PET with the radiolabeled glucose analogue 2-[F-18]-fluoro-2-deoxy-D-glucose. Radiology. 1991;179(3):765-770.

4. Bremer C, Ntziachristos V, Weitkamp B, Theilmeier G, Heindel W, Weissleder R. Optical imaging of spontaneous breast tumors using protease sensing 'smart' optical probes. Invest Radiol. 2005;40(6):321-327.

5. Montet X, Figueiredo JL, Alencar H, Ntziachristos V, Mahmood U, Weissleder R. Tomographic fluorescence imaging of tumor vascular volume in mice. Radiology. 2007;242(3):751-758.

6. Shukla R, Thomas TP, Peters JL, et al. HER2 specific tumor targeting with dendrimer conjugated anti-HER2 mAb. Bioconjug Chem. 2006; 17(5):1109-1115.

7. Olayioye MA. Intracellular signaling pathways of ErbB2/HER-2 and family members. Breast Cancer Res. 2001;3(6):385-389.

8. Slamon DJ, Godolphin W, Jones LA, et al. Studies of the HER-2/neu proto-oncogene in human breast and ovarian cancer. Science. 1989; 244(4905):707-712.

9. Pegram MD, Konecny GE, O'Callaghan C, Beryt M, Pietras R, Slamon DJ. Rational combinations of trastuzumab with chemotherapeutic drugs used in the treatment of breast cancer. J Natl Cancer Inst. 2004;96(10):739-749.

10. Montemurro F, Valabrega G, Aglietta M. Trastuzumab-based combination therapy for breast cancer. Expert Opin Pharmacother. 2004;52(1): 81-96.

11. Merlin JL, Barberi-Heyob M, Bachmann N. In vitro comparative evaluation of trastuzumab (Herceptin) combined with paclitaxel (Taxol) or docetaxel (Taxotere) in HER2-expressing human breast cancer cell lines. Ann Oncol. 2002;13(11):1743-1748.

12. Ferretti G, Felici A, Papaldo P, Fabi A, Cognetti F. HER2/neu role in breast cancer: from a prognostic foe to a predictive friend. Curr Opin Obstet Gynecol. 2007;19(1):56-62.

13. Xu Y, He B, Wang YJ, Fu Q. Effect of Herceptin combined with doxorubicin on rat cardiotoxicity. Ai Zheng. 2004;23(4):367-371. Chinese.

14. Rayson D, Richel D, Chia S, Jackisch C, van der Vegt S, Suter T. Anthracycline-trastuzumab regimens for HER2/neu-overexpressing breast cancer: current experience and future strategies. Ann Oncol. 2008;19(9):1530-1539.

15. Chen TJ, Cheng TH, Chen CY, et al. Targeted Herceptin-dextran iron oxide nanoparticles for noninvasive imaging of HER2/neu receptors using MRI. J Biol Inorg Chem. 2009;14(2):253-260.

16. Sun B, Ranganathan B, Feng S-S. Multifunctional poly(d,1-lactide-coglycolide)/montmorillonite (PLGA/MMT) nanoparticles decorated by trastuzumab for targeted chemotherapy of breast cancer. Biomaterials. 2008;29(4):475-486.

17. Cirstoiu-Hapca A, Bossy-Nobs L, Buchegger F, Gurny R, Delie F. Differential tumor cell targeting of anti-HER2 $\left(\right.$ Herceptin $\left.^{\circledR}\right)$ and antiCD20 (Mabthera ${ }^{\circledR}$ ) coupled nanoparticles. Int J Pharm. 2007;331(2): 190-196.
18. Anhorn MG, Wagner S, Kreuter J, Langer K, von Briesen H. Specific targeting of HER2 overexpressing breast cancer cells with doxorubicinloaded trastuzumab-modified human serum albumin nanoparticles. Bioconjug Chem. 2008;19(12):2321-2331.

19. Steinhauser I, Spänkuch B, Strebhardt K, Langer K. Trastuzumabmodified nanoparticles: optimisation of preparation and uptake in cancer cells. Biomaterials. 2006;27(28):4975-4983.

20. Steinhauser IM, Langer K, Strebhardt KM, Spänkuch B. Effect of trastuzumab-modified antisense oligonucleotide-loaded human serum albumin nanoparticles prepared by heat denaturation. Biomaterials. 2008;29(29):4022-4028.

21. Felt O, Buri P, Gurny R. Chitosan: a unique polysaccharide for drug delivery. Drug Dev Ind Pharm. 1998;24(11):979-993.

22. Agnihotri SA, Mallikarjuna NN, Aminabhavi TM. Recent advances on chitosan-based micro- and nanoparticles in drug delivery. J Control Release. 2004;100(1):5-28.

23. Avadi MR, Sadeghi AM, Mohammadpour N, et al. Preparation and characterization of insulin nanoparticles using chitosan and Arabic gum with ionic gelation method. Nanomedicine. 2010;6(1):58-63.

24. Atyabi F, Moghaddam FA, Dinarvand R, Zohuriaan-Mehr MJ, Ponchel G. Thiolated chitosan coated poly hydroxyethyl methacrylate nanoparticles: synthesis and characterization. Carbohydr Polym. 2008; 74(1):59-67.

25. Atyabi F, Talaie F, Dinarvand R. Thiolated chitosan nanoparticles as an oral delivery system for amikacin: in vitro and ex vivo evaluations. J Nanosci Nanotechnol. 2009;9(8):4593-4603.

26. Esmaeili F, Dinarvand R, Ghahremani MH, et al. Docetaxel-albumin conjugates: preparation, in vitro evaluation and biodistribution studies. J Pharm Sci. 2009;98(8):2718-2730.

27. Moghaddam FA, Atyabi F, Dinarvand R. Preparation and in vitro evaluation of mucoadhesion and permeation enhancement of thiolated chitosan-pHEMA core-shell nanoparticles. Nanomedicine. 2009;5(2): 208-215.

28. Akhlaghi SP, Saremi S, Ostad SN, Dinarvand R, Atyabi F. Discriminated effects of thiolated chitosan-coated pMMA paclitaxel-loaded nanoparticles on different normal and cancer cell lines. Nanomedicine. 2010; 6(5):689-697.

29. Saremi S, Atyabi F, Akhlaghi SP, Ostad SN, Dinarvand R. Thiolated chitosan nanoparticles for enhancing oral absorption of docetaxel: preparation, in vitro and ex vivo evaluation. Int J Nanomedicine. 2011;6:119-128.

30. Tan ML, Choong PF, Dass CR. Review: doxorubicin delivery systems based on chitosan for cancer therapy. J Pharm Pharmacol. 2009;61(2): 131-142.

31. Peniston P, Johnson EL, inventors. Process for depolymerization of chitosan. November 25, 1975. United States Patent 3922260.

32. Chuang W-Y, Young T-H, Yao C-H, Chiu W-Y. Properties of the poly(vinyl alcohol)/chitosan blend and its effect on the culture of fibroblast in vitro. Biomaterials. 1999;20(16):1479-1487.

33. El-Gibaly I. Development and in vitro evaluation of novel floating chitosan microcapsules for oral use: comparison with non-floating chitosan microspheres. Int J Pharm. 2002;249(1-2):7-21.

34. Son YJ, Jang J-S, Cho YW, et al. Biodistribution and anti-tumor efficacy of doxorubicin loaded glycol-chitosan nanoaggregates by EPR effect. J Control Release. 2003;91(1-2):135-145.

35. Hyung Park J, Kwon S, Lee M, et al. Self-assembled nanoparticles based on glycol chitosan bearing hydrophobic moieties as carriers for doxorubicin: in vivo biodistribution and anti-tumor activity. Biomaterials. 2006;27(1):119-126.

36. Hjelm H, Hjelm K, Sjöquist J. Protein A from Staphylococcus aureus. Its isolation by affinity chromatography and its use as an immunosorbent for isolation of immunoglobulins. FEBS Lett. 1972;28(1):73-76.

37. Ghose S, Hubbard B, Cramer SM. Binding capacity differences for antibodies and $\mathrm{Fc}$-fusion proteins on protein A chromatographic materials. Biotechnol Bioeng. 2007;96(4):768-779.

38. Coles DJ, Yang S, Minchin RF, Toth I. The characterization of a novel dendritic system for gene delivery by isothermal titration calorimetry. Biopolymers. 2008;90(5):651-654. 
39. Kocbek P, Obermajer N, Cegnar M, Kos J, Kristl J. Targeting cancer cells using PLGA nanoparticles surface modified with monoclonal antibody. J Control Release. 2007;120(1-2):18-26.

40. Zhu S, Hong M, Tang G, et al. Partly PEGylated polyamidoamine dendrimer for tumor-selective targeting of doxorubicin: the effects of PEGylation degree and drug conjugation style. Biomaterials. 2010; 31(6):1360-1371.

41. Zhu S, Hong M, Zhang L, Tang G, Jiang Y, Pei Y. PEGylated PAMAM dendrimer-doxorubicin conjugates: in vitro evaluation and in vivo tumor accumulation. Pharm Res. 2010;27(1):161-164.
42. Kakinoki A, Kaneo Y, Ikeda Y, Tanaka T, Fujita K. Synthesis of poly(vinyl alcohol)-doxorubicin conjugates containing cis-aconityl acid-cleavable bond and its isomer dependent doxorubicin release. Biol Pharm Bull. 2008;31(1):103-110.

43. Yoo HS, Lee EA, Park TG. Doxorubicin-conjugated biodegradable polymeric micelles having acid-cleavable linkages. $J$ Control Release. 2002;82(1):17-27.

44. Lu D, Liang J, Fan $\mathrm{Y}, \mathrm{Gu} \mathrm{Z}$, Zhang $\mathrm{X}$. In vivo evaluation of a $\mathrm{pH}-$ sensitive pullulan-doxorubicin conjugate. Adv Eng Mater. 2010;12(9): B496-B503.

\section{Publish your work in this journal}

The International Journal of Nanomedicine is an international, peerreviewed journal focusing on the application of nanotechnology in diagnostics, therapeutics, and drug delivery systems throughout the biomedical field. This journal is indexed on PubMed Central, MedLine, CAS, SciSearch ${ }^{\circledR}$, Current Contents ${ }^{\circledR} /$ Clinical Medicine,
Journal Citation Reports/Science Edition, EMBase, Scopus and the Elsevier Bibliographic databases. The manuscript management system is completely online and includes a very quick and fair peer-review system, which is all easy to use. Visit http://www.dovepress.com/ testimonials.php to read real quotes from published authors. 